\title{
OPEN Author Correction: Exfoliative toxin E, a new Staphylococcus aureus virulence factor with host-specific activity
}

Ichiro Imanishi, Aurélie Nicolas, Ana-Carolina Barbosa Caetano, Thiago Luiz de Paula Castro,

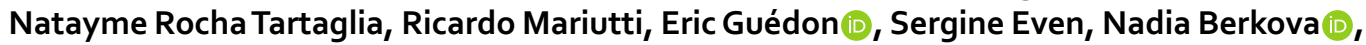
Raghuvir K. Arni, Nubia Seyffert, Vasco Azevedo, Koji Nishifuji \& Yves Le Loir (1)

Correction to: Scientific Reports https://doi.org/10.1038/s41598-019-52777-3, published online 08 November 2019

In the Supplementary Information file originally published with this Article, supplementary figure S6, showing Best HADDOCK solutions for ETE docking on Dsg1 of four animal species, and supplementary table S4, showing HADDOCK scores, were omitted. These errors have been corrected in the Supplementary Information that now accompanies the Article.

Due to the omitted figure and table, there were additional errors in the main body of the Article.

In the Results section, under the subheading 'Two types of docking orientation predicted',

"Docking simulations were also carried out with human and canine desmogleins (Supplementary Fig. S1) and displayed the same two ETE orientations."

now reads,

"Docking simulations were also carried out with human and canine desmogleins (Supplementary Fig. S6) and displayed the same two ETE orientations."

In the Experimental Procedures section, under the subheading 'Recombinant ete gene product',

"Purity of the ETE protein was determined by SDS-PAGE gels (Fig. S2)."

now reads,

"Purity of the ETE protein was determined by SDS-PAGE gels (Fig. S1)."

Under the subheading 'In vitro digestion of Dsg1 by ETs',

"Non-cropped, non-modified immunoblotting images for in vitro digestion of recombinant Dsg1 are presented in supplemental data (Fig. S3)."

now reads,

"Non-cropped, non-modified immunoblotting images for in vitro digestion of recombinant Dsg1 are presented in supplemental data (Fig. S2)." 
Additionally, there were typographical errors in the Experimental Procedures section, under the subheading 'Molecular docking',

"Residues involved in the active sites of both proteins were required. The active ETE residues were those defined in $^{9}$ (His96, Asp145 and Ser219) and those for Dsg1 were those defined in ${ }^{52}$ (Glu381, Gly382 in protein sequence matching Glu332, Gly333 in structural models)."

now reads,

"Residues involved in the active sites of both proteins were required. The active ETE residues were those defined in Mariutti et al..$^{9}$ (His96, Asp145 and Ser219) and those for Dsg1 were those defined in Hanakawa et al. ${ }^{52}$ (Glu381, Gly382 in protein sequence matching Glu332, Gly333 in structural models)."

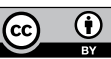

Open Access This article is licensed under a Creative Commons Attribution 4.0 International License, which permits use, sharing, adaptation, distribution and reproduction in any medium or format, as long as you give appropriate credit to the original author(s) and the source, provide a link to the Creative Commons license, and indicate if changes were made. The images or other third party material in this article are included in the article's Creative Commons license, unless indicated otherwise in a credit line to the material. If material is not included in the article's Creative Commons license and your intended use is not permitted by statutory regulation or exceeds the permitted use, you will need to obtain permission directly from the copyright holder. To view a copy of this license, visit http://creativecommons.org/licenses/by/4.0/.

(c) The Author(s) 2020 